\title{
Influence of cutting parameters on surface roughness for wet and dry turning process.
}

\begin{abstract}
This paper presents a study of the quality of a surface roughness model for mild steel with coated carbide cutting tool on turning process. The experiments were carried out under wet and dry cutting conditions. The model is developed based on cutting speed, feed and depth of cut as the parameters of cutting process. This research applies the fractional factorial design of experiment approach to studied the influence of cutting parameters on surface roughness. The measured results were collected and analyzed using commercial software package called Minitab. Analysis of variances is used to examine the influence of turning factors and factor interactions on surface roughness. The result indicated that, there are inherent differences in surface roughness between wet and dry cutting process with the same parameters process model. Analysis of variance was found that feed parameter is the most significant cutting parameter, which influences the surface roughness. The most significant interactions were found between cutting speed and feed parameters for dry turning process. Therefore is a significant effect of using combination of the fluid for cooling the cutting operation.
\end{abstract}

Keyword: Design of Experiment (DoE); Parameters Process; Surface Roughness (SR); Turning. 